Fukushima J. Med. Sci.,

Vol. 56, No. 1, 2010

[Original Article]

\title{
NON-ANTIBIOTIC TREATMENT FOR PEDIATRIC OUTPATIENTS WITH COMMON COLD INHIBITS THE EMERGENCE OF DRUG RESISTANT PNEUMOCOCCI
}

\author{
AYUMI MATSUMOTO ${ }^{1)}$, AYA TAKEYAMA ${ }^{2)}$, KOICHI HASHIMOTO ${ }^{1)}$, MASAKI ITO ${ }^{1)}$, \\ MASAHIKO KATAYOSE ${ }^{2}$, KAZUO KATO ${ }^{3)}$, YUKIHIKO KAWASAKI ${ }^{1)}$ \\ and MITSUAKI HOSOYA ${ }^{1)}$ \\ ${ }^{1)}$ Department of Pediatrics, Fukushima Medical University, Fukushima, Japan, ${ }^{2)}$ Department of Pediatrics, Soma \\ General Hospital, Fukushima, Japan, ${ }^{3)}$ Department of Pediatrics, Fujita General Hospital, Fukushima, Japan
}

(Received January 16, 2009, accepted March 26, 2010)

\begin{abstract}
The occurrence of drug resistant Streptococcus pneumoniae (S. pneumoniae) is very high in Japan. Unnecessary use of antibiotics had been thought to cause this problem but previous studies had not clearly showed that the decreasing rate of antibiotic use had been related to the reduction of the prevalence of resistant strains. In this study, we tried to prove that non-antibiotic treatment for common cold would reduce the antibiotic resistant $S$. pneumoniae in nasopharynx in children. Forty-five children with the common cold were randomly selected from pediatric patients who had taken antibiotics within the past three months. We collected nasopharyngeal swabs from all of the participants and once again after a period of 2 to 3 months without using any antibiotics. Twenty-four of these patients had the $S$. pneumoniae strains isolated. Then these strains were undergone a susceptibility test and drug-resistant gene detection. The susceptibility test reveled that patients with penicillin-resistant strains decreased from 17 to $7(p<0.01)$. The test also reveled that the decreased number of patients had strains that were resistant to cefditren. The gene detection revealed that none of the patients acquired a higher resistance to penicillin. Our study suggests that the treatment without antibiotics reduces the drug-resistant S. pneumoniae. Controlled antibiotic use in children might prevent children from carrying the antibiotic resistant S. pneumoniae.
\end{abstract}

Key words : Steptococcus pneumoniae, antibiotics, common cold, child

\section{INTRODUCTION}

The occurrence of multi-drug resistant Streptococcus pneumoniae (S. pneumoniae) is very high in Japan. We previously reported about characteristics of nasopharyngeal isolates

松本歩美, 武山 彩, 橋本浩一, 伊藤正樹, 片寄雅彦, 加藤一夫, 川崎幸彦, 細矢光亮

Corresponding author : Ayumi Matsumoto E-mail : b-walk@fmu.ac.jp

http://fmu.ac.jp/home/lib/F-igaku/ http://www.sasappa.co.jp/online/ 
from children. The study revealed that $88.5 \%$ of $S$. pneumoniae had more than one $p b p$ gene alteration that indicated strains would be resistant to beta-lactams and $84.5 \%$ of $S$. pneumoniae had mefA gene or/and $\mathrm{erm} B$ gene alteration that indicated the strains would be resistant to macrolides ${ }^{1)}$. We also found that more than half of the patients who came to our hospital with common cold were given antibiotics without signs of bacterial infection and that previous antibiotic use had a close relationship to the alteration of $p b p$ genes in S. pneumoniae. Then, we considered if we would medicate the children with less antibiotics, the resistant rate would decrease.

Worldwide, risk factors for the carriage of resistant S. pneumoniae have been well investigated in the last couple of decades ${ }^{2-16)}$ and those studies reported that the most influencing factor was the previous use of antibiotics. Unnecessary use of antibiotics had been thought to cause this emergence of antibiotic resistant S. pneumoniae. On the basis of this theory, previous studies were performed to show the dynamics between antibiotic use and the rate of resistant S. pneumoniae ${ }^{17,18)}$. But it seemed to be difficult to demonstrate that the less use of antibiotic clearly reduce the prevalence of resistant strains. We considered one of the reasons why they could not demonstrate the reduction of resistant strains was that the researchers investigated a large number of the mass but not the change in individuals. Therefore, we tried to investigate the nasopharyngeal $S$. pneumoniae in specific patients. We did not prescript the antibiotics to them within a certain period and tested their isolates. The purpose of this study is to analyze the change of drug-resistance in those isolates before and after the antibiotic free term.

METHOD

\section{Study design}

This study was performed as a prospective trial in Soma general hospital, in the northern part of Japan, from November 2003 to July 2004. In this area, there is only one pediatric clinic and seven clinics that treat children. Patients with common cold on "walk-in" were excluded. We also excluded the patients that showed signs of bacterial infection, such as the high concentration of $\mathrm{C}$ reactive protein (CRP) more than $5 \mathrm{mg} / \mathrm{dl}$ and an increasing numbers of white blood cell (WBC) more than $20,000 / \mu \mathrm{L}$. We chose patients who had taken antibiotics within the past three months and 134 patients were considered to be suitable for this study. Out of those 134 patients, 45 patients were chosen at random to enroll into this study. Informed consent was administered to all the participants and their families. Nasopharyngeal swabs were also collected at this time. We did not use any type of antibiotic treatment and the participants agreed that they would not receive any antibiotics treatment from other clinics or hospitals during the term of this trial if it would not be necessary. Follow-up examinations were performed after 2 or 3 months to all patients.

\section{Bacterial isolates}

The nasopharyngeal swabs were plated on $5 \%$ sheep blood agar, and then incubated for 24 hours. Out of colonies showed alpha-hemolysis, a major colony was picked up and incu- 
Table 1. Characteristics of patients

\begin{tabular}{cc}
\hline Characteristics & $n[\%](N=24)$ \\
Male & $19[79.2]$ \\
Age (months old) & 60 \\
Maximum & 2 \\
Minimum & 15.3 \\
Mean & $17[70.8]$ \\
Day care attendance & $16[66.7]$ \\
Having sibling & \\
Type of antibiotic & $19[79.2]$ \\
Beta-lactams & $5[20.8]$ \\
Macrolides & \\
Merm of antibiotic medication (days) & 7 \\
Maximum & 3 \\
Minimum & 4.9 \\
\hline
\end{tabular}

bated for another 24 hours, and identified as $S$. pneumoniae by Optochin test (Optochin Showa Disc ; Nissui Phamaceutical, Tokyo) and a latex coagulating reaction test (Slidex pneumo-Kit ; BioMerieux, France) was also done to these samples. Antimicrobial susceptibility to four antibiotics, such as penicillin, cefditren, erythromycun, clarithromycin were also tested with a broth micro dilution test (MICroFAST Panel Type3J-T MicroScan; Dade Behring, USA), in accordance with the previous standards of National Committee for Clinical Laboratory Standards (currently called Clinical Laboratory and Standards Institute). Then each of the individual strains was determined by minimum inhibitory concentration (MIC) against antibiotics. These strains were also tested to detect antibiotic-resistant genes. Altered $p b p$ genes, namely, $p b p 1 a, p b p 2 x$, and $p b p 2 b$, and macrolide-resistant genes, namely, $m e f A$ and $\operatorname{erm} B$ were determined by polymerase chain reaction (PCR), using a commercially available primer mixture (Wakunaga Pharmaceutical, Hiroshima, Japan) that included the oligonucleotide primers for detecting the resistant genes. We could confirm the strains as $S$. pneumonia at a molecular level since the primer mixture also included the primer for detecting lytA, a specific gene in S. pneumoniae.

\section{Patients' background}

The patients' background including, age, sex, daycare attendance, sibling and antibiotic used within past 3 months were taken into account by a questionnaire and/or by referring to medical records.

\section{Statistical Analysis}

We assessed the differences using the T test, the outcomes of MIC test and the number of strains with drug resistant genes using the $\chi 2$ test. If the value of $\mathrm{P}$ was less than 0.05 , then the result was considered statistically significant. 


\section{S. pneumoniae isolation}

Out of the 45 participants, we detected 30 strains at the initial test. Out of the 30 strains, 24 strains were still evident in the second examination.

\section{Characteristics of host patients}

All of the patients recovered without any problem. Table 1 shows the characteristics of the patients. There were $79.2 \%{ }^{19)}$ male and the median age was 15.3 months. Day care attendance was $70.8 \%{ }^{17)}$. Children with sibling(s) were $66.7 \%^{16)}$. There were $79.2 \%{ }^{19}$ patients who had taken beta-lactams and $20.8 \%{ }^{5)}$ patients had taken macrolides within the past 3 months before the test. The mean term of antibiotic medication was 5 days.

\section{Outcome of the MIC range}

Fig. 1 shows outcome of the MIC distribution against four antibiotics. Fig. 1 (a) shows the number of penicillin-resistant strains (MIC $\geqq 0.12 \mathrm{mg} / \mathrm{L}$ ) that were decreased from $70.8 \%^{17)}$ to $29.2 \%^{7)}(p<0.01)$. Also, it clearly shows a peak of MIC shifts from $2 \mathrm{mg} / \mathrm{L}$ to 0.06 $\mathrm{mg} / \mathrm{L}$. Fig. 1 (b) shows the decrease in the number of strains those showed resistant to cefditren (MIC $\geqq 0.5 \mathrm{mg} / \mathrm{L}$ ) from $66.7 \%^{16)}$ to $25.0 \%{ }^{6)}(p<0.01)$ and it shows a peak of MIC shifts

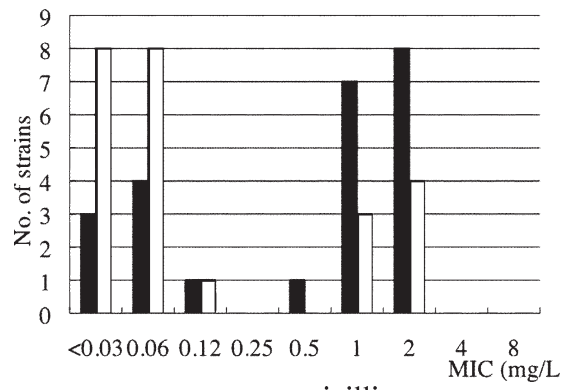

(a) penicillin

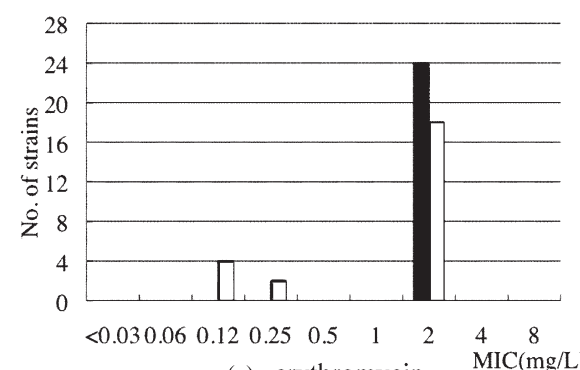

(c) erythromycin

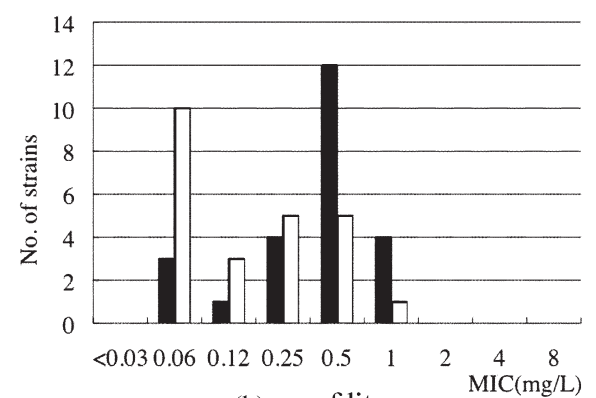

(b) cefditren

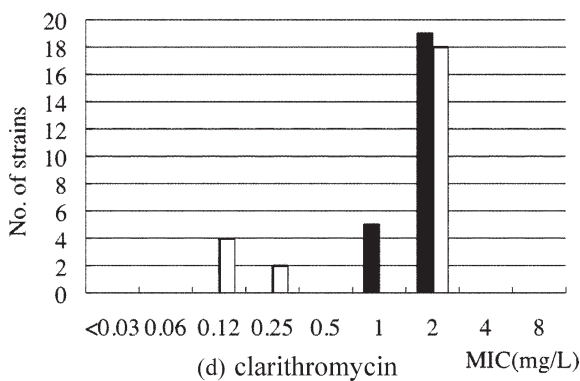

(d) clarithromycin

Fig. 1. MIC distribution for antibiotics against beta-lactams. Streptococcus pneumoniae isolated at the initial and second test were determined their MIC by penicillin (a), cefditren (b), erythromycin (c), and clarithromycin (d). Black bars and white bars indicate the initial and second test, respectively. 
Table 2. Results of altered $p b p$ gene detection at the initial and second tests

\begin{tabular}{cccc}
\hline & initial & second & $P$ value \\
\hline $1 \mathrm{a}+2 \mathrm{x}+2 \mathrm{~b}$ & 15 & 7 & 0.005 \\
$1 \mathrm{a}+2 \mathrm{x}$ & 2 & 3 & 0.194 \\
$2 \mathrm{x}+2 \mathrm{~b}$ & 0 & 1 & 0.105 \\
$2 \mathrm{x}$ & 4 & 4 & 0.354 \\
no altered gene & 3 & 9 & 0.013 \\
\hline
\end{tabular}

Table 3. Results of macrolide-resistant gene detection at the initial and second tests

\begin{tabular}{cccc}
\hline & initial & second & $P$ value \\
\hline mefA+ermB & 5 & 1 & 0.024 \\
mefA & 4 & 5 & 0.158 \\
ermB & 14 & 13 & 0.217 \\
none & 1 & 5 & 0.024 \\
\hline
\end{tabular}

from $0.5 \mathrm{mg} / \mathrm{L}$ to $0.06 \mathrm{mg} / \mathrm{L}$. Fig. 1 (c) and 2 (d) show the decrease in the number of strains those showed resistant to erythromycin (MIC $\geqq 1 \mathrm{mg} / \mathrm{L}$ ) from $24(100 \%)$ to $18(75.0 \%)$ $(p<0.01)$, and to clarithromycin (MIC $\geqq 1 \mathrm{mg} / \mathrm{L})$ from $24(100 \%)$ to $18(75.0 \%)(p<0.01)$. However, peaks of MIC to those macrolides were located at the similar point during testing.

\section{Outcome of gene detection}

Table 2 displays the results of $p b p$ gene detection during testing. There was a decrease in numbers of strain with 3 -points alteration $(1 \mathrm{a}+2 \mathrm{x}+2 \mathrm{~b})$ of $p b p$ genes from $62.5 \%{ }^{15)}$ to $29.2 \%^{7)}(p<0.01)$. Strains without altered $p b p$ gene showed an increase in the number from $12.5 \%^{3)}$ to $37.5 \%^{9)}(p=0.04)$. Table 3 displays that the results of macrolide-resistant gene detection in both groups. There was a decrease in numbers of strains with both mefA and ermB genes from $20.8 \%^{5)}$ to $4.2 \%^{1)}(p=0.02)$. Strains without macrolide-resistant gene showed an increase in numbers from $4.2 \%^{1)}$ to $20.8 \%^{5)}(p=0.02)$.

\section{Change of the resistant gene of $S$. pneumoniae in individuals}

Fig. 2 shows dynamics of the $p b p$ gene alteration of S. pneumoniae in 24 patients. The graph clearly exhibits that there is no patient who had the strain acquired altered $p b p$ gene(s). In the 11 patients (group A), the strains had a decreased number of $p b p$ gene alteration and in the rest of the 13 patients (group B) the strains remained the same gene(s) during the two tests. Table 4 shows the term from the medication to the initial test (the antibiotic-free term) in the both group A and group B. There is no statistical difference between the two groups. Fig. 3 shows change of the macrolide-resistant gene in those patients. In the 2 patients, the strains acquired a macrolide-resistant gene and in the rest of 22 patients, the strains had the less resistant gene or the same gene(s) during the two tests. 


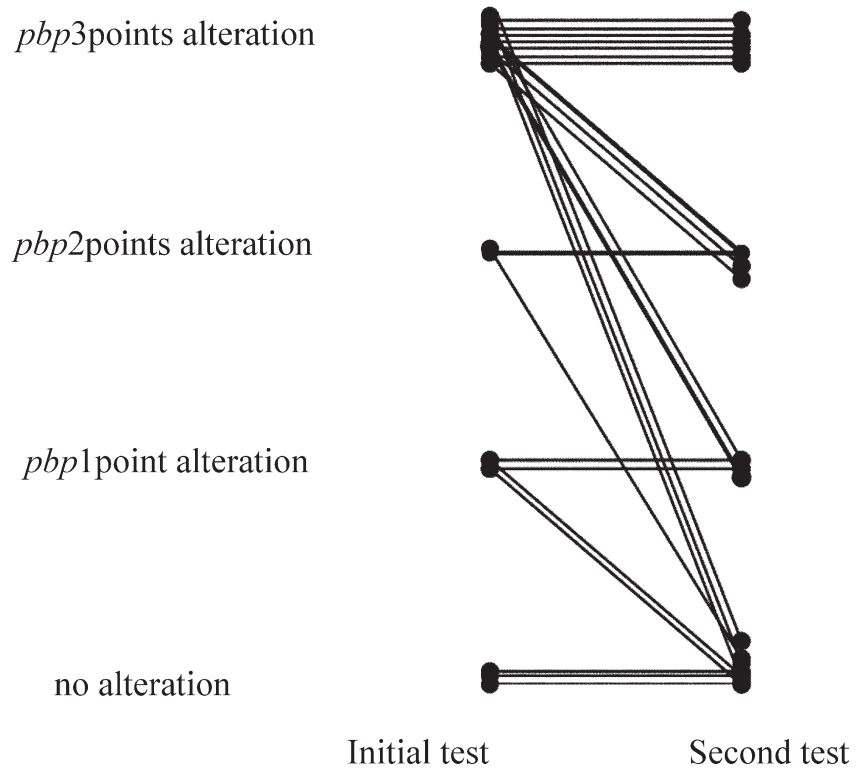

Fig. 2. Change of the pbp gene alteration of Streptococcus pneumoniae at the initial and the second test in individuals. The black dots indicate the each patient.

\section{DISCUSSION}

Penicillin-resistant S. pneumonie was first isolated in the late 1980's and has rapidly spread throughout our country ${ }^{19)}$. Currently, it is known that the prevalence of those strains is very high as recent reports showed the rate is higher than $80 \%^{20,21)}$. Other reports also mentioned that the rate of macrolide-resistant strains has increased and that the rate is higher than $80 \%$. It has been considered that unnecessary use of antibiotics in our country cause these problems ${ }^{19)}$. We believe that the most important factor is controlled antibiotic use to prevent the emergence of resistant $S$. pneumonaie. In this study, we have tried to prove that drug-resistant $S$. pneumoniae in nasopharynx of children would improve with no antibiotic use.

According to the results of the MIC test, penicillin-resistant strains and strains with resistance against cephalosporin antibiotics showed a decrease. These are consistent with the results of gene detection. There were 11 patients in whom the numbers of altered $p b p$ gene had decreased and of those eleven patients, 6 patients showed an improvement from strains with altered $p b p$ genes to strains having no $p b p$ gene alteration. The detection also revealed that there was no patient who had the strain acquired altered $p b p$ gene(s). The MIC peaks against to erythromycin and clarithromycin did not change afterwards. The macrolideresistant gene detection showed a decline in the strains with both mefA and ermB but two strains had acquired a macrolide-resistant gene. These outcomes propose that the antibiotic free term might inhibit the emergence of resistant strains especially against beta-lactams but the further control study is needed to prove the effect of antibiotic free term on resistant 
Table 4. The antibiotic free term in the group A and the group B

\begin{tabular}{cccc}
\hline & group A & group B & $P$ value \\
\hline maximam & 174 & 165 & \\
minimum & 81 & 90 & \\
median & 143 & 116 & 0.850 \\
mean & 131.3 & 122.4 & 0.447 \\
\hline
\end{tabular}

* The group A includes the patients who had the strain with a decreased number of altered pbp gene(s)

** The group B includes the patients who had the strain with the same altered pbp gene(s) during the two tests

Both mefA and ermB

$$
\text { mefA or ermB }
$$

none

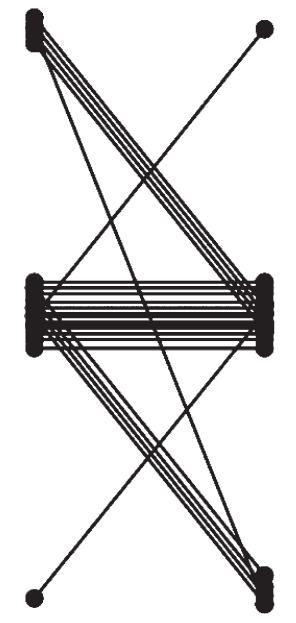

$$
\text { Initial test }
$$

Second test

Fig. 3. Change of the macrolide-resistant gene of Streptococcus pneumoniae at the initial and the second test in individuals. The black dots indicate the each patient.

genes to be replaced by normal genes.

In this study, we found there were 11 patients in whom the numbers of altered $p b p$ gene had decreased but on the other side, the strains remained to have the same gene in more than half of all patients. We compared the antibiotic free term between the patients with less altered $p b p$ gene(s) and the patients with same gene(s) but there was no statistical difference. We should test the samples more frequently and follow up longer to define how long will genes take to change. Or some environmental facts as having siblings, attending daycare nursery and age might influence on the patients in those the strains did not show an improvement. We should also continue to analyze more patients to define the reason why some strains did not recover antibiotic susceptibility even after the period of free from antibiotic selecting pressure.

This study has several limitations. Firstly, the rate of resistant strains was quite high at 
the initial test. We predicted a high resistant rate when we started this study since the occurrence of resistant S. pneumoniae was very high in this area ; more than $80 \%{ }^{1)}$ and all the patients enrolled in this study had taken antibiotics before the study. Secondly, the method of $S$. pneumoniae isolation could cause a possible bias because only a single colony of S. pneumoniae was examined from each patient in this study. Since strains from the nasopharynx are considered to have various susceptibilities against antibiotics this single colony might not reflect a suitable resistant rate. It would be logical to assume that susceptible strains became predominant under no antibiotic selecting pressure.

Some studies prescribe a pneumococcal conjugate vaccine as an effective way not to materialize of invasive pneumococcal disease ${ }^{24,25)}$. This may reduce incidences of persistent antibiotic-resistant $S$. pneumoniae infection but does not mean antibiotic-resistant S. pneumoniae will vanish. Even though human being will continue producing new drugs in the future, the resistances to those drugs will also follow in time. Therefore, we consider that the best way to prevent the emergence of antibiotic-resistant pneumococci is not to use antibiotics for all patients who do not require the medication as a source of treatment. We believe this is a simple way that will contribute to improve the threatening state of S. pneumoniae around Japan and the world.

\section{ACKNOWLEDGEMENT}

We would like to thank the technical support of Kyoko Hirasawa and Kumiko Sugama in the Bacteriological Laboratory of Fukushima Institute of Public Health and the technical support of Kiyohiko Watanabe and Kinuko Ara in the Bacteriological Laboratory of Soma General Hospital.

\section{REFERENCES}

1. Matsumoto A, Hosoya M, Kawasaki Y, Katayose M, Kato K, Suzuki H. The Emergence of Drugresistant Streptococcus pneumoniae and Host Risk Factors for Carriage of Drug-Resistant Genes in the Northeastern Region of Japan. Jpn J Infect Dis, 60 : 10-13, 2007.

2. Ussery XT, Gessner BD, Lipman H, Elliott JA, Crain MJ, Tien PC, Parkinson Aj, Davidson M, Facklam RR. Braiman RF. Risk factors for nasopharyngeal carriage of resistant Streptcoccus pneumoniae and detection of a multiply resistant clone among children living in the Yukon-Kuskukwim Delta Region of Alaska. Pediatr Infect Dis J, 15 : 986-992, 1996.

3. Arnold KE, Leggiadro RJ, Breiman RF, Lipman HB, Schwartz B, Appleton MA, Cleveland KO, Szeto HC, Hill BC, Tenover FC, Elliot JA, Facklam RR. Risk factors for carriage of dug-resistant Streptococcus pneumoniae among children in Menphis, Tennessee. J Pediatr, 128 : 757-764, 1996.

4. Arason VA, Kristinsson, KG, Sigurdsson JA, Stefánsdóttir G, Möslad S, Gudmundsson S. Do antimicrobials increase the carriage rate of penicillin resistant pneumococci in children? Cross sectional prevalence study. British Medical Journal, 313 : 387-391, 1996.

5. Clavo-Sánchez AJ, Girón-González JA, López-Prieto D, Canuetto-Quentero A, Marin-Casanova P, Córdoba-Dofia JA. Multivariate analysis of risk factors for infection due to penicillin-resistant and mutidrug-resistant Streptococcus pneumoniae : A multicenter study. Clin Infect Dis, 24 : 1052 1059, 1997.

6. Kristinsson KG. Effect of antimicrobial use and other risk factors on antimicrobial resistant in pneumococci. Microb Drug Resist, 3 : 117-123, 1997. 
7. Melander E, Mölstad S, Pesson K, Hasson HB, Söderstöm M, Ekdahl K. Previous antibiotic consumption and other risk factors for carriage of penicillin-resistant Streptococcus pneumoniae in children. Eur J Microbiol Infect Dis, 17 : 834-838, 1998.

8. Deeks SL, Palasio R, Ruvinsky R, Kertesz DA, Hortal M, Rossi A, Sika JS, Fabio JLD. The Streptococcus pneumoniae working group Risk factors and Course of illness among children with invasive penicillin-resistant Streptcoccus pneumoniae. Pediatrics, 103 : 409-413, 1999.

9. Syrogiannopoulos GA, Grivea IN, Tavies TA, Katopodis GD, Applebaum PC, Bertis N. Antimicrobial use and colonization with erythromycin-resistant Streptcoccus pneumoniae in Greece during the First 2 years of life. Clin Infect Dis, 311 : 887-893, 2000.

10. Samore MH, Magill MK, Alder SC, Severina E, Boer LM, Lyon JL, Carroll K, Leary J, Stone MB, Bradford D, Readin J, Tomasz A, Sande MA. High rates of multiple antibiotic resistance in Streptcoccus pneumoniae from healthy children living in isolated rural communities : Association with cephalosporin use and intrafamilial transmission. Pediatrics, 108 : 856-865, 2001.

11. Pihlajamaki M, Kotilainen P, Kaurila T, Palva E, Huovinen P, the Finnish Atudy Group for Antimicrobial Resistance. Macrolide-resistant Streptcoccus pneumoniae and use of antimicrobial agents. Clin Infect Dis, 33 : 483-488, 2001.

12. Marc L. Measuring and interpreting associations between antibiotics use and penicillin resistance in Streptcoccus pneumoniae. Clin Infect Dis, 32 : 1044-1054, 2001.

13. Lipsitch M, Samore M. Antibiotic use and antimicrobial resistance: A population perspective. Emerg Infect Dis, 8 : 342-354, 2002.

14. Nasrin D, Collignon PJ, Roberts L, Wison EJ, Piotto LS Douglas RM. Effect of $\beta$ - lactam antibiotic use in children on pneumococcal resistance to penicillin : morospective cohort study. British Medical Jounal, 5 : 324-328, 2002.

15. Beekmann EE, Diekema D, Heilmann KP, Richter SS, Doer GV. Macrolide use identified as risk factor for macrolide-resistant Streptcoccus pneumoniae in a 17 -center case-control study. Eur J Clin Microbiol Infect Dis, 6 : 33-44, 2006.

16. Guillemot D, Carsbon C, Balkau B, Geslin P, Lecoeur H, Vauzelle-Kervroedan F, Bouvenot G, Ecshwege E. Low dosage and long treatment duration of $\beta$-lactam. Risk factors for carriage of penicillin-resistant Streptcoccus pneumoniae. JAMA, 279 : 365-370, 1997.

17. Barkai G, Greenberg D, Givon-Lavi N, Dreifuss E, Vardy D, Dagan R. Community prescribing and resistant Streptcoccus pneumoniae. Emerg Infect Dis, 11 : 829-837, 2005.

18. Hsueh PR. Decreasing rates of resistance to penicillin, but not erythromycin, in Streptococcus pneumoniae after introduction of apolicy to restrict antibiotic usage in Taiwan. Microbiol Infect, 11 : 925-927, 2005.

19. Ubukata K. Problems associated with high prevalence of multidrug-resistant bacteria in patients with community-acquired infectious. J Infect Chemother, 9 : 285-291, 2004.

20. Ubukata K, Chiba N, Hasegawa K, Kobayashi R, Iwata S, Sunakawa K. Antibiotic Susceptibility in Relation to Penicillin-Binding Protein Genes and Serotype Distribution of Streptococcus pneumoniae Strains Responsible for Meningitis in Japan, 1999 to 2002. Antimicrob Agents Chemother, 48: 1488-1494, 2004.

21. Chiba N, Kobayashi N, Hasegawa K, Morozumi M, Nakayama E, Tajima T, Iwata S, Ubukata K. Antibiotic susceptibility according to genotype of penicillin-binding protein and macrolide resistance genes, and serotype of Streptococcus pneumoniae isolates from community-acquired pneumonia in children. J Antimicrob Chemother, 56 : 756-760, 2005.

22. Sunakawa K, Farrell D. Mechanisms, molecular and sero-epidemiology of antimicrobial resistance in bacterial respiratory pathogens isolated from Japanese children. Ann Clin Microbiol Antimicrob, 6 : 7-14, 2007.

23. Isozumi R, Ito Y, Ishida T, Osawa M, Hirai T, Ito I, Maniwa K, Hayashi M, Kagioka H, Hirabayashi M, Onari K, Tomioka H, Tomii K, Gohma I, Imai S, Takakura S, Iinuma Y, Ichiyama S, Mishima M, the Kansai Community Acquired Pneumococcal Pneumonia Study Group. Genotypes and Related Factors Reflecting Macrolide Resistance in Pneumococcal Pneumonia Infections in Japan. J Clin Microbiol, 45 : 1440-1446, 2007.

24. Kyaw MH, Lynfield R, Schaffner W, Creig AS, Hadler J, Reingold A, Thomas AR, Harrison LH, 
Bennett N, M Farley MM, Facklam RR, Jorgensen JH, Besser J, Zell E, Schuchat A, Whitney CG. Effect of introduction of the pneumococcal conjugate vaccine on drug-resistant Streptcoccus pneumoniae. N Eng J Med, 354 : 1455-1463, 2006.

25. Frazão N, Brito-Avô A, Simas C, Saldanha J, Mato R, Nunes A, Sousa NG, Carrico JA, Almeida JS, Santos-Sanches L, de Lencastre H. Effect of the seven-valent conjugate pneumococcal vaccine on carriage and drug resistance of Streptcoccus pneumoniae in healthy children attending day-care centers in Lisbon. Pediatr Infect Dis J, 24 : 243-252, 2005. 